\title{
Predictors of low urinary quality of life in spinal cord injury patients on clean intermittent catheterization
}

\author{
Iryna M. Crescenze MD $^{1}$ @ I Jeremy B. Myers MD $^{2} \mid$ Sara M. Lenherr MD, MS $^{2}$ | \\ Sean P. Elliott MD, MS ${ }^{3}$ | Blayne Welk MD, MSc $^{4}{ }^{4}$ | Diana O'Dell, MPH ${ }^{1}$ | \\ Yongmei Qin ${ }^{1}$ | Angela P. Presson PhD $^{2}$ | John T. Stoffel MD $^{1}$ | \\ for the Neurogenic Bladder Research Group
}

${ }^{1}$ Department of Urology, University of Michigan, Ann Arbor, Michigan

${ }^{2}$ Division of Urology, University of Utah, Salt Lake City, Utah

${ }^{3}$ Department of Urology, University of Minnesota, Minneapolis, Michigan

${ }^{4}$ Division of Urology, Western University, London Ontario, Toronto, Canada

\section{Correspondence}

Iryna M. Crescenze, Female Pelvic Medicine and Reconstructive Urology Fellow, Department of Urology, University of Michigan Medical Center 1500 E Medical Center Dr SPC 5330, Ann Arbor, MI 48109

Email: iryna.crescenze@gmail.com

Funding information

Patient-Centered Outcomes Research Institute Award, Grant/Award Number: CER14092138

\begin{abstract}
Objective: Clean intermittent catheterization (CIC) is a preferred method of bladder management for many patients with spinal cord injury (SCI), but longterm adherence is low. The aim of this study is to identify factors associated with low urinary quality of life (QoL) in SCI adults performing CIC.

Methods: Over 1.5 years, 1479 adults with SCI were prospectively enrolled through the Neurogenic Bladder Research Group registry, and 753 on CIC with no prior surgeries were included. Injury characteristics, complications, hand function, and Neurogenic Bladder Symptom Score (NBSS) were analyzed. The NBSS QoL question (overall satisfaction with urinary function) was dichotomized to generate comparative groups (dissatisfied vs neutral/satisfied).
\end{abstract}

Results: The cohort was $32.9 \%$ female with a median age of 43.2 (18-86) years, time since the injury of 9.8 (0-48.2) years, and $69.0 \%$ had an injury at T1 or below. Overall $36.1 \%$ were dissatisfied with urinary QoL. On multivariable analysis, female gender (odds ratio [OR], 1.63; 95\% confidence interval [CI], 1.15-2.31; $P=0.016$ ), earlier injury (OR, 0.95 per year; 95\% CI, 0.93-0.97; $P<0.001), \geq 4$ urinary tract infections (UTIs) per year (OR, 2.36; 95\% CI, 1.47-3.81; $P=0.001$ ), and severe bowel dysfunction (OR, 1.42; 95\% CI, 1.02-1.98; $P=0.035)$ predicted dissatisfaction. Level of injury, fine motor hand function, and caregiver dependence for CIC were not associated with dissatisfaction.

Conclusions: In a mature SCI cohort, physical disability does not predict dissatisfaction with urinary QoL but severe bowel dysfunction and recurrent UTIs have a significant negative impact. With time the rates of dissatisfaction decline but women continue to be highly dissatisfied on CIC and may benefit from early intervention to minimize the burden of CIC on urinary QoL.

\section{K E Y W O R D S}

clean intermittent catheterization, neurogenic bladder, patient-reported outcomes, spinal cord injury 


\section{INTRODUCTION}

Over $75 \%$ of patients with spinal cord injury (SCI) are not able to spontaneously empty his/her bladder and require a bladder management strategy. ${ }^{1}$ Clean intermittent catheterization (CIC) is a safe and effective first-line treatment option for patients with SCI with reasonable storage capacity. It is associated with fewer complications as opposed to indwelling catheters in patients with $\mathrm{SCI}^{2}$ However, population studies have found that only about $50 \%$ of patients with SCI use CIC as the primary bladder management method after the initial injury, and $50 \%$ of patients with SCI on CIC drop-out at 5 years of follow up. ${ }^{1}$ Female sex, elevated body mass index (BMI), older age, high level of injury/tetraplegia, and impaired upper extremity motor function decreased the odds of bladder management with CIC. ${ }^{1,4,12}$

Limited data are available on patient-reported barriers to CIC. Patients who discontinue CIC have reported inconvenience, dislike of CIC, recurrent urinary tract infections (UTIs), incontinence, urethral strictures, and dependence on caregiver as the most common reasons to switch bladder management in small single-center reports. ${ }^{3,5}$ A survey of 269 patients found that men who are not able to perform CIC cited limited hand function as the most common reason, while women reported inability to sit appropriately for CIC, with limited hand function being the second most common reason that required caregiver assistance with CIC. $^{6}$

Considering the low proportion of patients on longterm CIC despite the potential benefits there is a need to understand and address patient-reported barriers to satisfaction with CIC. The primary aim of this study is to identify clinical and demographic factors that correlate with dissatisfaction with the overall bladder-related quality of life (QoL) among adult SCI population managed with CIC. Our proposed hypothesis was that high level of injury and increasing physical disability, diminished hand function, or the need for caregiver assistance with CIC led to diminished bladder-related QoL in SCI.

\section{MATERIALS AND METHODS}

A multi-institutional collaborative study group prospectively enrolled adult SCI people between 1 January 2016 to 30 June 2017 in a QoL registry regarding satisfaction with bladder management. Adults with acquired SCI who were able to communicate in English and answer web-based questionnaires were included in the study. Patients with congenital or progressive lesions were excluded. The details on trial protocol and methods have been previously published. ${ }^{7}$ The study was approved by the internal review board for each institution participating (Trial Registration: NCT0261608, www.clinicaltrials.gov; HSRP20153564, US National Library of Medicine, wwwcf.nlm.nih.gov).

The study enrolled 1479 patients over 1.5 years. This analysis includes baseline data for patients on CIC per urethra as the primary bladder management and excluded any patients with prior surgical reconstruction of the bladder such as bladder augmentation, catheterizable channel, or both. Patient self-reported demographic, clinical, injury information, and history of bladderrelated complications were collected. Neurogenic Bladder Symptom Score (NBSS), ${ }^{8}$ Neurogenic Bowel Dysfunction Score (NBD), ${ }^{9}$ SCI-QoL including the fine motor function index subdomain ${ }^{10}$ and modified SCI SF-12 ${ }^{11}$ were administered and this data was included in the analysis.

Level of injury was classified into three categories based on the anatomic likelihood of preserved upper extremity function: $\mathrm{C} 4$ and above, $\mathrm{C} 5-\mathrm{C} 8$, and $\mathrm{T} 1$ and below. ${ }^{12}$ Because patient-reported data was used, Americal Spinal Injury Association (ASIA) classification was not uniformly available, instead, patient self-reported classification of complete vs incomplete injury was included. Fine motor function scores as evaluated by the SCI-QoL questionnaire are reported as a continuous number and higher scores indicate better function. ${ }^{13}$ Fine motor scores were classified based on the ability level as described by Sinha et $\mathrm{al}^{14}$ : Level 1 (Score, $\leq 32$ )—no activities requiring hand function, Level 2 (Score, 33-43)-some activities involving gross hand movement, Level 3 (Score, 44-51)-some activities requiring dexterity and co-ordinated upper extremity movement, Level 4 (Score, $\geq 52$ ) -most activities requiring dexterity and co-ordinated upper extremity movement. Severe bowel dysfunction was defined as a score of $>14$ on NBD questionnaire. ${ }^{9}$ Frequency of UTIs was self-reported and classified as none, 1 to 3 , or $>4$ infections over the past year. Patients who reported performing CIC independently some or all of the time were classified as independent CIC as opposed to those requiring caregiver assistance for all CIC episodes. Obesity was defined as BMI $\geq 30 \mathrm{~kg} / \mathrm{m}^{2}$.

The NBSS QoL question was used as the primary outcome measure. Validated for neurogenic bladder assessment, it asks about patient satisfaction with urinary function and contains five possible answers including unhappy, mostly unsatisfied, mixed, mostly satisfied, and pleased. This variable was used to generate dichotomized comparative groups by combining those who are unhappy/ mostly unsatisfied into dissatisfied vs those who were either mixed, mostly satisfied, or pleased into neutral/ satisfied. Patient and injury characteristics, comorbidities, complications, and upper extremity function variables 
associated with dissatisfaction with current bladder management were identified using univariate analysis.

\section{1 | Statistical methods}

SAS (version 9.4; SAS Institute Inc, Cary, NC) was used for statistical analyses. Continuous variables were summarized as mean \pm standard deviation or median (range), and discrete variables were summarized as percent and count. Dissatisfaction with bladder-related QoL was compared with categorical variables using $\chi^{2}$ tests and with continuous variables using the Student $t$ tests. A multivariable logistic regression model was used to identify independent predictors of dissatisfaction with urinary QoL on CIC. The model accounted for clinically relevant factors such as age, sex, obesity, education, time since injury, level of injury, need for caregiver assistance for CIC and variables that showed significant association on univariate analysis with $P<0.1$. Secondary outcomes included NBSS total scores, and SF-12 mental and physical health scores and were compared using the Student $t$ tests. Statistical significance was assessed at the 0.05 level.

\section{3 | RESULTS}

Out of 2284 patients screened, 1479 patients met the inclusion criteria and were enrolled in the study. Of the total cohort 753 patients identified as using CIC for primary bladder management (Figure 1). The median age of the cohort was 43.2 (18-86) years and self-reported median time from injury was 9.8 (0-48) years. Twenty-eight percent (212 of 752) patients had Botulinum Toxin A injections. Details of patient baseline characteristics are outlined in Table 1.

Patients were using CIC for a median of 9.5 (0-44) years since the injury and $10.9 \%(82 / 752)$ relied on the caregiver for CIC. Diminished hand function (Level 1-3) was reported by over $30 \%$ of patients (Table 1). Patients with higher injury were more likely to have diminished fine motor function (Level 1-3; 84.1\%, 83.0\%, and 7.0\% for $\mathrm{C} 4$ and above, C5-C8, T1 and below, respectively, $P<0.001)$ and were more likely to rely on caregiver for CIC $(58.3 \%, 23.5 \%$, and $1.4 \%$ for $\mathrm{C} 4$ and above, C5-C8, T1 and below respectively, $P<0.001$; Figure 2).

Patients were dichotomized into two groups based on satisfaction with bladder management (NBSS QoL). Thirty-six percent (272/753) were dissatisfied with urinary QoL on CIC. The average urinary QoL scores for patients dissatisfied was $3.5 \pm 0.5$ vs $1.4 \pm 0.7$ for those neutral/satisfied $(P<0.001)$. The NBSS total score was $30.8 \pm 12.0$ for patients dissatisfied with bladder QoL on CIC vs $23.1 \pm 9.6$ for those who were neutral/satisfied $(P<0.001)$ indicating worse symptoms. This difference was significant in each subdomain including incontinence, storage and voiding, and consequences (Figure 2A). In addition, patients dissatisfied with urinary QoL on CIC reported decreased physical and emotional health as measured by SF-12 compared with those neutral/ satisfied (Figure 2B).

Patients dissatisfied with their bladder QoL on CIC were more likely to be female $(41.2 \%$ [112/272] vs $28.3 \%$ [136/461], $P<0.001)$, younger (40.1 [18.0-86.0] vs 45.4 [19.1-78.5] years, $P=0.002)$, have a more recent injury (6.0 [0.17-48.2] vs 12.3 [0-44.8] years, $P<0.001)$, have $\geq 4$ UTIs/year (38.2\% [104/272] vs $21.8 \%$ [105/481], $P<0.001)$, severe bowel dysfunction (43.0\% [117/272] vs 31.8\% [153/ 481], $P=0.002)$ and chronic pain $(71.6 \%$ [194/272] vs $63.3 \%$ [305/480], $P<0.022$ ) (Table 1). Level of injury, complete vs incomplete SCI, mobility, obesity, use of Botulinum toxin, autonomic dysreflexia, impaired SCI-QoL fine motor function (both as continuous and categorical variables), and caregiver dependence for CIC were not associated with dissatisfaction with on NBSS QoL (Table 1).

On multivariable analysis including age, sex, obesity, education, level of injury, caregiver reliance for CIC, and chronic pain female sex (odds ratio [OR], 1.63; 95\% confidence interval [CI], 1.15-2.31; $P=0.016), \geq 4$ UTIs/ year (OR, 2.36; 95\% CI, 1.47-3.81; $P=0.001$ ), and bowel dysfunction (OR, 1.42; 95\% CI, 1.02-1.98; $P=0.035$ ) predicted dissatisfaction with bladder QoL for patients performing CIC (Table 2). The odds of dissatisfaction with bladder-related QoL while performing CIC decreased by about 5\% per year after injury (OR, 0.95; 95\% CI, 0.92-0.97; $P<0.001)$. Neither the level of injury or caregiver dependence for CIC predicted dissatisfaction with bladder-related QoL. Fine motor function score was correlated

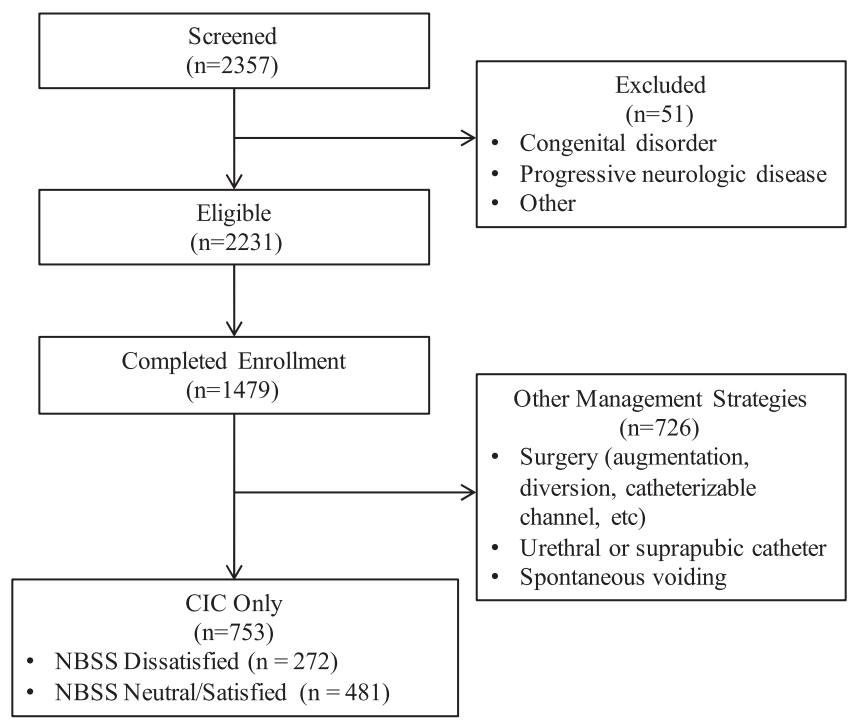

F I G U RE 1 Patient cohort selection. CIC, clean intermittent catheterization; NBSS, Neurogenic Bladder Symptom Score 
TABLE 1 Cohort demographic and clinical information

\begin{tabular}{|c|c|c|c|c|}
\hline & Total $(n=753)$ & Neutral/satisfied $(n=481)$ & Dissatisfied $(n=272)$ & $P$ values \\
\hline \multicolumn{5}{|l|}{ Patient characteristics } \\
\hline Age, y & $43.2(18.0-86.0)$ & $45.4(19.1-78.5)$ & $40.1(18.0-86.0)$ & $0.002^{*}$ \\
\hline BMI & $25.1(12.1-52.0)$ & $25.1(15.7-52.0)$ & $25.1(12.1-49.1)$ & 0.572 \\
\hline Completed college & $39.8 \%(299 / 752)$ & $42.0 \%(202 / 481)$ & $35.8 \%(97 / 271)$ & 0.095 \\
\hline Mobility_able to stand & $12.9 \%(97 / 752)$ & $12.7 \%(61 / 481)$ & $13.3 \%(36 / 271)$ & 0.813 \\
\hline Botulinum toxin injections & $28.2 \%(212 / 752)$ & $26.3 \%(126 / 480)$ & $31.6 \%(86 / 272)$ & 0.118 \\
\hline $\begin{array}{l}\text { Upper extremity function } \\
\text { Fine motor score }\end{array}$ & $55.8(26.9-65.9)$ & $56.3(26.9-65.9)$ & $55.6(26.9-65.9)$ & 0.631 \\
\hline $\begin{array}{l}\text { Fine motor score level } \\
\text { Level } 1 \\
\text { Level } 2 \\
\text { Level } 3 \\
\text { Level } 4\end{array}$ & $\begin{array}{c}1.1 \%(8 / 743) \\
7.3 \%(54 / 743) \\
22.1 \%(164 / 743) \\
69.6 \%(517 / 743)\end{array}$ & $\begin{array}{c}0.8 \%(4 / 474) \\
8.7 \%(41 / 474) \\
20.3 \%(96 / 474) \\
70.3 \%(333 / 474)\end{array}$ & $\begin{array}{c}1.5 \%(4 / 269) \\
4.8 \%(13 / 269) \\
25.3 \%(68 / 269) \\
68.4 \%(184 / 269)\end{array}$ & 0.105 \\
\hline $\begin{array}{l}\text { Injury level } \\
\text { C4 and above } \\
\text { C5-C8 } \\
\text { T1 and below }\end{array}$ & $\begin{array}{c}8.2 \%(60 / 735) \\
22.7 \%(167 / 735) \\
69.1 \%(508 / 735)\end{array}$ & $\begin{array}{c}7.1 \%(33 / 468) \\
24.4 \%(114 / 468) \\
68.6 \%(321 / 468)\end{array}$ & $\begin{array}{l}10.1 \%(27 / 267) \\
19.9 \%(53 / 267) \\
70.0 \%(187 / 267)\end{array}$ & 0.172 \\
\hline $\begin{array}{l}\text { Complications and comorbidities } \\
\text { Autonomic dysreflexia } \\
>4 \text { UTIs per year } \\
\text { UTI-related hospitalization within } 12 \text { mo } \\
\text { Chronic pain } \\
\text { Severe bowel dysfunction }\end{array}$ & $\begin{array}{l}43.3 \%(297 / 686) \\
27.8 \%(209 / 753) \\
10.4 \%(78 / 753) \\
66.3 \%(498 / 751) \\
35.9 \%(270 / 753)\end{array}$ & $\begin{aligned} 41.4 \% & (183 / 442) \\
21.8 \% & (105 / 481) \\
9.6 \% & (46 / 481) \\
63.3 \% & (305 / 480) \\
31.8 \% & (153 / 481)\end{aligned}$ & $\begin{array}{l}46.7 \%(114 / 244) \\
38.2 \%(104 / 272) \\
11.8 \%(32 / 272) \\
71.6 \%(194 / 271) \\
43.0 \%(117 / 272)\end{array}$ & $\begin{array}{r}0.178 \\
<0.001^{*} \\
0.341 \\
0.022^{*} \\
0.002^{*}\end{array}$ \\
\hline
\end{tabular}

Abbreviations: BMI, body mass index; CIC, clean intermittent catheterization; UTI, urinary tract infection *Statistically significant

with the level of injury and did not significantly change the outcome of the multivariate model when used instead of the level of injury $\left(r_{\mathrm{s}}=0.67 ; P<0.001\right)$. Time on CIC and time from injury were highly correlated, and thus time from injury was included in the regression model because it was not biased by patient recall $\left(r_{\mathrm{s}=0.94 ;} P<0.001\right)$.

\section{4 | DISCUSSION}

CIC is a safe, effective, and reliable long-term bladder management option for patients with SCI. However, only $50 \%$ of spinal cord injured adults use CIC after the initial injury and usage decline over time with as high as a 50\% drop-out rate at 5 years. ${ }^{1}$ There is a need to better understand the reasons for patient dissatisfaction with CIC to address patient concerns, improve compliance, and offer alternative treatments sooner. In this mature cohort of 753 SCI patients using CIC, we found that female sex, frequent UTIs, bowel dysfunction, and shorter time since injury played a major role in low patient satisfaction scores with bladder-related QoL on
CIC. We also found that level of injury, caregiver dependence for CIC, and the upper extremity fine motor function did not influence patient dissatisfaction rates.

This study addresses a gap in patient-perceived dissatisfaction with bladder-related QoL on CIC as compared with provider and caregiver attitudes. While CIC is widely recommended after SCI by providers as a long-term bladder management strategy for men and women, we found that women in this cohort were almost twice as likely to be dissatisfied with their bladder QoL while on CIC, independent of other variables. Performing CIC in women poses increased complexity, in general, compared with performing CIC in men. ${ }^{15}$ Prior studies in spinal cord populations showed that female sex predicted poor adherence with $\mathrm{CIC}^{1,4}$ and this study demonstrates that women with mature, long-term spinal cord injuries continue to be dissatisfied with CIC. It is likely because access to the urethra is more challenging for women compared with men and women may need to reposition to successfully perform CIC. ${ }^{6,26}$ Walsh et $\mathrm{al}^{17}$ observed that women with cervical SCI may need as up to 27 minutes to perform $\mathrm{CIC}^{16}$ and may be more likely than 

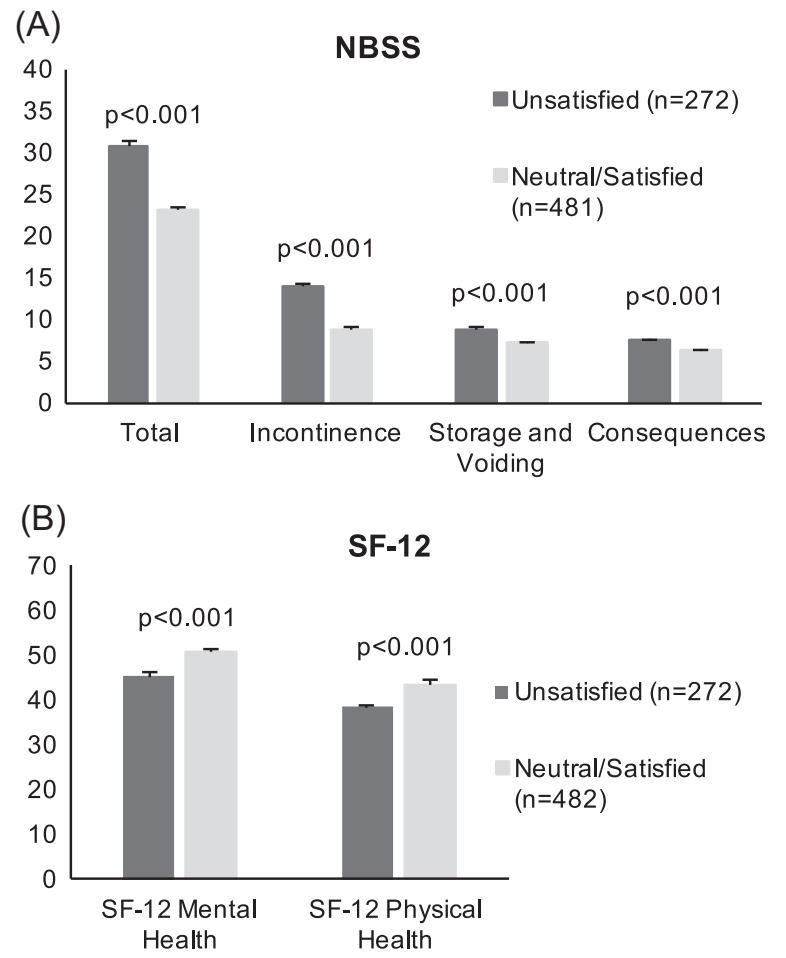

F I G U RE 2 Relationship of SF-12 physical and emotional health and NBSS outcomes with patient-reported satisfaction with their bladder-related QoL on CIC. CIC, clean intermittent catheterization; NBSS, Neurogenic Bladder Symptom Score; QoL, quality of life

men to require caregiver assistance when catheterizing. In addition, other studies have noted that women can perceive CIC as intrusive, shameful, and aversive, ${ }^{6,15}$ which may further play a role in overall dissatisfaction with CIC. Further more specific studies are needed to better understand the role of sexuality in relation to CIC.

Although obesity in female patients has been suggested as a barrier to CIC and has been previously linked to the decreased rate of CIC adherence after initial rehabilitation discharge in a study of 665 women with $\mathrm{SCI},{ }^{12}$ we did not identify obesity as a variable that impacted satisfaction rates with CIC in the long-term. This may be due to the lower number of obese women in our cohort (22.2\% or 55/193), which limited the power of this subgroup analysis. However, the finding may also be due to the cross-sectional nature of the recruitment for the study. Patients with significant physical barriers to CIC likely did not pursue this bladder management strategy and thus would not be included in this cohort.

This study showed that patients with CIC who suffered from $\geq 4$ UTIs/year are almost two times more likely to express dissatisfaction with their bladder-related QoL. This is logical since patients with SCI with frequent UTIs are likely to experience worsening neurogenic bladder symptoms, including exacerbation of incontinence and spasticity. Other authors have also identified UTIs as a predictor of change in
TABLE 2 Logistic regression model of predictors of patient dissatisfaction with bladder related QoL on CIC

\begin{tabular}{|c|c|c|}
\hline & \multicolumn{2}{|c|}{$\begin{array}{l}\text { Multivariate Logistic } \\
\text { regression NBSS QoL }\end{array}$} \\
\hline & OR and $95 \% \mathrm{CI}$ & $P$ values \\
\hline $\begin{array}{l}\text { Patient characteristics } \\
\text { Age, y } \\
\text { Female sex } \\
\text { Obese }(\mathrm{BMI}>30) \\
\text { Completed college } \\
\text { Caregiver dependence for CIC }\end{array}$ & $\begin{array}{l}1.00(0.99-1.02) \\
1.63(1.15-2.31) \\
1.04(0.69-1.55) \\
0.87(0.62-1.23) \\
0.73(0.39-1.36)\end{array}$ & $\begin{array}{l}0.881 \\
0.007^{*} \\
0.864 \\
0.428 \\
0.318\end{array}$ \\
\hline $\begin{array}{l}\text { Injury description } \\
\text { Years since injury }\end{array}$ & $0.95(0.93-0.97)$ & $<0.001^{*}$ \\
\hline $\begin{array}{l}\text { Injury level } \\
\text { C4 and above vs T1 below } \\
\text { C5-C8 vs T1 and below }\end{array}$ & $\begin{array}{l}1.67(0.84-3.30) \\
0.87(0.57-1.34)\end{array}$ & 0.173 \\
\hline $\begin{array}{l}\text { Complications and comorbidities } \\
\text { UTI number } \\
>4 \text { UTIs per year vs none } \\
\text { >4 UTIs per year vs none }\end{array}$ & $\begin{array}{l}2.36(1.47-3.81) \\
1.39(0.90-2.14)\end{array}$ & $0.001^{*}$ \\
\hline $\begin{array}{l}\text { Chronic pain } \\
\text { Severe bowel dysfunction }\end{array}$ & $\begin{array}{l}1.21(0.85-1.73) \\
1.42(1.02-1.98)\end{array}$ & $\begin{array}{l}0.288 \\
0.035^{*}\end{array}$ \\
\hline
\end{tabular}

OR for continuous variable reported per unit change in regressor. BMI, body mass index; CI, confidence interval; $\mathrm{CIC}$, clean intermittent catheterization; NBSS, Neurogenic Bladder Symptom Score; OR, odds ratio; UTI, urinary tract infection

*Statistically significant

bladder management among SCI people. Afsar et $\mathrm{al}^{3}$ demonstrated that symptomatic UTIs along with symptoms of urinary incontinence are some of the common reasons why patients with SCI switch bladder management strategies. Given the significant impact of UTIs on the overall health and satisfaction with bladder-related QoL on CIC based on our findings, we suggest that providers should discuss more aggressive UTI management, work to identify and manage the causes of UTIs or seek early alternative bladder management strategies.

Bowel dysfunction is an important consideration for patients with neurogenic bladder and has a significant impact on the patient's functioning and QoL. ${ }^{18}$ In this analysis, severe bowel dysfunction correlated with dissatisfaction with urinary QoL. While true for patients on CIC, prior studies showed a close correlation of bowel dysfunction with urinary scores in SCI cohort overall. ${ }^{19}$ Further work is needed to better understand the relationship between various bladder management strategies and the severity of bowel symptoms. Providers can assist patients with developing better management strategies for bowel dysfunction and should address this early in the course of injury.

We found that the odds of dissatisfaction with bladderrelated QoL on CIC decreased by about 5\% per year since injury. Initially, after injury, CIC has a significant learning curve and appropriate education, access to the bathroom 
facilities at a regular interval, prosthetic devices, and caregiver support is imperative. ${ }^{20,26}$ Patients who are not able to establish a reasonable routine, due to lack of social support or logistical means to allow for timely CIC, are more likely to move on to a different management strategy soon after injury. Thus, it is not surprising that patients who remain on CIC in the long-term become well-adjusted and are less likely to be dissatisfied with their selected management as found in this study.

We hypothesized that hand function, caregiver dependence for CIC, and the injury level would predict urinary QoL but we did not find a significant relationship. A number of studies examined predictors of the overall QoL in patients with SCI and while some were able to demonstrate a direct effect of disability on the QoL, others could not confirm these findings with only a weak relationship noted on metaanalysis. ${ }^{21}$ While physical disability is an important determinant of the overall health, it is not directly related to the QoL but is rather a basis for the social handicap, which subsequently impacts the overall QoL. ${ }^{22}$ A path model proposed by Post et $\mathrm{al}^{23}$ proposes that the injury and patient demographics interplay to outline the overall patientperceived physical and mental health, which in turn determines social functioning, and along with age and marital status, then shapes the overall QoL. Previous research has shown that limited hand function leads to the decreased likelihood of CIC initiation at the time of initial injury and increased rates of CIC discontinuation at 1 year. ${ }^{4}$ Our data suggest that in the long-term hand function no longer plays a direct role in bladder-related QoL outcomes in patients with SCI performing CIC. However, we did find a direct relationship of the urinary QoL on CIC and SF-12 physical and mental health scores. These findings are consistent with the path model where actual physical disability does not directly translate to QoL outcomes in the long-term but is rather altered by psychosocial functioning and adaptation.

Pain is a common secondary diagnosis with SCI and is reported by $26 \%$ to $100 \%$ of patients. ${ }^{24}$ It has been shown to be associated with worse QoL outcomes in $\mathrm{SCI}^{24}$ In this cohort, $66.3 \%$ of patients suffered from chronic pain. On univariate analysis, we found that pain was associated with low bladder-related QoL but after accounting for patient and injury characteristics this was no longer significant. Chronic pain was more often reported by younger patients (OR, 3.33; 95\% CI, 1.49-7.48; $P=0.003$ ), those with $\geq 4$ UTIs/year (OR, 1.99; 95\% CI, 1.29-3.09; $P=0.005$ ), and less often by college graduates (OR, 0.64; 95\% CI, 0.47-0.87; $P=0.004$ ). Chronic pain was not an independent predictor of dissatisfaction with urinary QoL on CIC for this mature SCI cohort.

It is important to note the limitations of this study. Participants in the study were highly educated with about $40 \%$ having completed a college degree or higher as compared to $22 \%$ at 10 years after SCI in the National SCI Database. ${ }^{25}$ Participants had access to electronic resources and had time to complete online questionnaires. This cohort may be more motivated than average to be an active participant in the health care process, and thus may have better follow up compliance, and overall better clinical outcomes. Also, this is an analysis of crosssectional data and we are not able to comment on how perceptions changed over time. It largely represents a patient cohort with mature SCI-the average time since injury was $>13$ years. Many patients had been on CIC for over 12 years and were well accustomed to their selected bladder management. Care should be taken when applying these findings to patients with a newly sustained injury. While some factors, such as hand function, do not play a role in patient satisfaction in the long-term they may be important in the first year after injury when social and environmental logistics are not yet established and patients learn to adapt to the new physical deficits. NBSS QoL question assesses satisfaction with urinary QoL. All the patients in this cohort were managed with CIC and thus primary outcome measured patient perceptions with urinary QoL on CIC. Some of the variables examined including recurrent UTIs, bowel dysfunction, and chronic pain may be associated with worse urinary QoL regardless of management choice and further work is needed to better understand these relationships.

\section{5 | CONCLUSIONS}

CIC remains an excellent long-term management option for patients with SCI however about $1 / 3$ of patients continue to be dissatisfied with urinary QoL. While upper extremity fine motor function is linked to the level of injury and need for caregiver assistance with CIC it does not independently predict dissatisfaction with bladder-related QoL in the long-term. Female sex is independently associated with dissatisfaction with CIC on multivariate analysis. Recurrent UTIs play a major role in urinary QoL on CIC and aggressive UTI prevention protocols and evaluation for new-onset infections is warranted. With time patients either adapt or discontinue to selected bladder management and are more likely to be satisfied with CIC. This analysis is limited to baseline data and further analysis of the longitudinal data will be used to better understand how patient perceptions change over time.

\section{ACKNOWLEDGMENT}

Patient Centered Outcomes Research Institute AwardCER14092138. 


\section{ORCID}

\section{Iryna M. Crescenze (i) http://orcid.org/0000-0002-} 0453-0573

Blayne Welk (10) http://orcid.org/0000-0001-7093-558X

\section{REFERENCES}

1. Cameron AP, Wallner LP, Tate DG, Sarma AV, Rodriguez GM, Clemens JQ. Bladder management after spinal cord injury in the United States 1972 to 2005. J Urol. 2010;184(1):213-217. https://doi.org/10.1016/j.juro.2010.03.008

2. Weld KJ, Dmochowski RR. Effect of bladder management on urological complications in spinal cord injured patients. $J$ Urol. 2000;163(3):768-772. https://doi.org/10.1016/S0022-5347(05)67800-7

3. Afsar SI, Yemisci OU, Cosar SNS, Cetin N. Compliance with clean intermittent catheterization in spinal cord injury patients: a long-term follow-up study. Spinal Cord. 2013;51(8):645-649. https://doi.org/10.1038/sc.2013.46

4. Zlatev DV, Shem K, Elliott CS. Predictors of long-term bladder management in spinal cord injury patients-upper extremity function may matter most. Neurourol Urodyn. 2017;35(23 ): 1106-1112. https://doi.org/10.1002/nau.23430

5. Lane GI, Driscoll A, Tawfik K, Chrouser K. A cross sectional study of the catheter management of neurogenic bladder after traumatic spinal cord injury. Neurourol Urodyn. 2017;36(1):360-367. https:// doi.org/10.1002/nau.23306

6. Yılmaz B, Akkoç Y, Alaca R, et al. Intermittent catheterization in patients with traumatic spinal cord injury: obstacles, worries, level of satisfaction. Spinal Cord. 2014;52(11):1-5. https://doi. org/10.1038/sc.2014.134

7. Patel DP, Lenherr SM, Stoffel JT, et al. Study protocol: patient reported outcomes for bladder management strategies in spinal cord injury. BMC Urol. 2017;17(1):1-9. https://doi.org/10.1186/ s12894-017-0286-3

8. Welk B, Carlson K, Baverstock R. A pilot study of the responsiveness of the Neurogenic Bladder Symptom Score (NBSS). Can Urol Assoc J. 2017;11(12):11-13. https://doi. org/10.5489/cuaj.4833

9. Krogh K, Christensen P, Sabroe S, Laurberg S. Neurogenic bowel dysfunction score. Spinal Cord. 2006;44(10):625-631. https://doi.org/10.1038/sj.sc.3101887

10. Tulsky DS, Jette AM, Kisala PA, et al. Spinal cord injuryfunctional index: item banks to measure physical functioning in individuals with spinal cord injury. Arch Phys Med Rehabil. 2012;93(10):1722-1732. https://doi.org/10.1016/j.apmr.2012.05.007

11. Ware JE, Kosinski M, Keller SD. A 12-item short-form health survey: construction of scales and preliminary tests of reliability and validity. Med Care. 1996;34(3):220-233. https://doi.org/10. 1097/00005650-199603000-00003

12. Zlatev DV, Shem K, Elliott CS. How many spinal cord injury patients can catheterize their own bladder? The epidemiology of upper extremity function as it affects bladder management. Spinal Cord. 2016;54(4):287-291. https://doi.org/10.1038/sc.2015.169

13. Jette AM, Tulsky DS, Ni P, et al. Development and initial evaluation of the spinal cord injury-functional index. Arch Phys Med Rehabil. 2012;93(10):1733-1750. https://doi.org/10.1016/j.apmr.2012.05.008

14. Sinha R, Slavin MD, Kisala PA, Ni P, Tulsky DS, Jette AM. Functional ability level development and validation: providing clinical meaning for spinal cord injury functional index scores. Arch Phys Med Rehabil. 2015;96(8):1448-1457. https://doi.org/ 10.1016/j.apmr.2014.11.008

15. Bakke A, Irgens LM, Malt UF, Hoisreter PA. Clean intermittent catheterisation performing abilities, aversive experiences and distress. Paraplegia. 1993;31(5):288-297. https://doi.org/10.1038/ sc.1993.52

16. Cameron AP, Rodriguez GM, Gursky A, He C, Clemens JQ, Stoffel JT. The severity of bowel dysfunction in patients with neurogenic bladder. J Urol. 2015;194(5):1336-1341. https://doi. org/10.1016/j.juro.2015.04.100

17. Walsh K, Troxel SA, Stone AR. An assessment of the use of a continent catheterizable stoma in female tetraplegics. BJU Int. 2004;94(4):595-597. https://doi.org/10.1111/j.1464-410X.2004. 05007.x

18. Yavuzer G, Gök H, Tuncer S, Soygür T, Arikan N, Arasil T. Compliance with bladder management in spinal cord injury patients. Spinal Cord. 2000;38(12):762-765. http://www.ncbi. nlm.nih.gov/pubmed/11175377

19. Liu C, Huang C, Yang $\mathrm{Y}$, Chen S, Weng $M$, Huang $M$. Relationship between neurogenic bowel dysfunction and healthrelated quality of life in persons with spinal cord injury. $J$ Rehabil Med. 2009;41(1):35-40. https://doi.org/10.2340/16501977-0277

20. Le Breton F, Guinet A, Verollet D, Jousse M, Amarenco G. Therapeutic education and intermittent self-catheterization: recommendations for an educational program and a literature review. Ann Phys Rehabil Med. 2012;55(3):201-212. https://doi. org/10.1016/j.rehab.2012.01.006

21. Dijkers M. Quality of life after spinal cord injury: a meta analysis of the effects of disablement components. Spinal Cord. 1997;35(12):829-840. https://doi.org/10.1038/sj.sc.3100571

22. Post M, Noreau L. Quality of life after spinal cord injury. J Neurol Phys Ther. 2005;29(3):139-146. https://doi.org/10.1016/ B978-0-323-00699-6.10023-1

23. Post MW, de Witte LP, van Asbeck FW, van Dijk a J, Schrijvers a J. Predictors of health status and life satisfaction in spinal cord injury. Arch Phys Med Rehabil. 1998;79(4):395-401. https:// doi.org/10.1016/S0003-9993(98)90139-3

24. Putzke JD, Richards JS, Hicken BL, DeVivo MJ. Interference due to pain following spinal cord injury: important predictors and impact on quality of life. Pain. 2002;100(3):231-242. https:// doi.org/10.1016/S0304-3959(02)00069-6

25. National Spinal Cord Injury Statistical Center. Spinal cord injury facts and figures at a glance. J Spinal Cord Med. 2012;35(1):68-69. https://doi.org/10.1179/204577212X13237783484262

26. Bolinger R, Engberg S. Barriers, complications, adherence, and self-reported quality of life for people using clean intermittent catheterization. J Wound, Ostomy Continence Nurs. 2013;40(1): 83-89. https://doi.org/10.1097/WON.0b013e3182750117

How to cite this article: Crescenze IM, Myers JB, Lenherr SM, et al. Predictors of low urinary quality of life in spinal cord injury patients on clean intermittent catheterization. Neurourology and Urodynamics. 2019;38:1332-1338.

https://doi.org/10.1002/nau.23983 